\title{
Making sure that the world's palaeodata do not get buried
}

\section{International efforts are keeping information accessible.}

Sir - Your Opinion article "Make the most of palaeodata" (Nature 411, 1; 2001) called for public funding of palaeoclimatic research, more interdisciplinary collaboration and the systematic archiving of data.

The International GeosphereBiosphere programme's core project on past global changes (PAGES) (http://www. pages-igbp.org) and the World Data Center for Paleoclimatology (http://www. ngdc.noaa.gov/paleo) exist specifically to address these needs, including facilitating interdisciplinary collaboration, providing publicly available palaeoenvironmental data archives, and coordinating the efforts of the "maze of publicly supported databases".

For more than a decade, the World Data Center for Paleoclimatology (WDC-Paleo), hosted by the National Oceanic and Atmospheric Administration (NOAA) Paleoclimatology Program in Boulder, Colorado, has been working to ensure that palaeoclimate data are freely available. Serving as the PAGES international palaeodata system, WDC-Paleo houses myriad proxy data from thousands of sites. PAGES and WDC-Paleo collaborate with the research community and international partners to provide a long-term, open archive of these important data.

Many agencies and journals are already helping to promote data sharing. In the United States, the National Science Foundation (NSF), the NOAA and the US Global Change Research Program have strong data-sharing policies. The NSF/NOAA initiative on Earth system history requires as a condition of funding that data are submitted to WDC-Paleo. The journals Paleoceanography and Journal of Paleolimnology both encourage authors to submit their data to WDCPaleo, and Science now requires archival data to be deposited in a publicly accessible database. We encourage more journals to require or request submission of data to internationally approved public archives.

PAGES, WDC-Paleo and the many scientists and institutions that support them have made great efforts to make data easily accessible and usable.

Agencies funding palaeoclimate research must be committed to providing resources for investigators to prepare their data for inclusion, and for data centres to maintain free, open,

international archives of palaeoclimate data and the tools to access them.

Keith Alverson ${ }^{\star}$, C. Mark Eakin $\dagger$

${ }^{*}$ PAGES International Project Office, Bärenplatz 2, Bern CH-3011, Switzerland $\dagger$ NOAA Paleoclimatology Program and World Data Center for Paleoclimatology, NOAA/National Geophysical Data Center, 325 Broadway E/GC, Boulder, Colorado 80305-3328, USA

\section{Who will organize sharing of biodiversity data?}

Sir - I welcome your Opinion article (Nature 411, 1; 2001) drawing attention to the issue of how to share the exploding palaeodata relevant to global change. Few of us have begun to face up to the methodological, legal and cultural implications, let alone thought about how to process the data for greatest value.

The issues go far wider than those covered in your Opinion article, leading from palaeodata to information from palaeontology and biodiversity of modern organisms. Data from all these sources need to be assessed and integrated before combined analyses in the interdisciplinary approaches that will be required to understand the latest environmental challenges.

Recent attempts to build multi-query information-technology systems for biodiversity data are struggling for money and an agreed methodology.

Various databases are separately available on the Internet, covering palaeodata (http://www-odp.tamu.edu); the fossil record, through the International Organisation of Palaeobotany (http://ibs.uel.ac.uk/palaeo); modern species, through the International Organization for Plant Information (http://iopi.csu.edu.au/iopi) and the Man and the Biosphere project (http:// ice.ucdavis.edu/mab); and quaternary ecosystems through the World Data Center for Paleoclimatology's global pollen database (http://www.ngdc.noaa.gov/ paleo/ftp-pollen.html). But these

databases have resisted the integration that is technically possible.

An example of a multi-query system is now available at http://biodiversity.org.uk, where it is possible to query more than 20 databases at different locations (click on 'search data' and then 'Java-enabled version'). For example, if one uses the wild card $^{\star}$ and searches for Sal ${ }^{\star}$, one will receive details of salmon, Salmonella, Salix, salt, salamander and so on from databases situated in the Philippines, Japan, Australia, London and California, respectively.

The OECD is taking responsibility for some of the biodiversity data. It is time to expand the support to include these other fast-growing data as well.

One central multidisciplinary agency, such as the International Council for Science or UNESCO, must be in control. Who is to make the nomination? Michael Boulter Palaeobiology Research Unit, University of East London, Romford Road, London E15 4LZ, UK

\section{Mistaken identity in a watery arms race}

Sir - The thought-provoking Concepts essay "A watery arms race" by Victor Smetacek (Nature 411, 745; 2001) concerns defence systems in the phytoplankton, yet the illustration shows a testate amoeba — neither planktonic nor photosynthetic!

I like to think that most students of freshwater biology 20 years, even 10 years, ago would have recognized the incongruity. But what leaves me frightened for the future of wholeorganism biology is that Nature, the prestige biology journal, should be guilty of such a howler.

Doubtless the picture was sought in a hurry and in the interests of immediacy. This is all very well for those who set store by citation indices, but the consequence is that the article may be mentioned as much for the wrong reasons (as an example of the demise of whole-organism biology) as for the right ones. It is scarcely fair to the author, to his interesting ideas or to our discipline.

Richard M. Crawford

Friedrich Hustedt Diatom Collection, Alfred Wegener Institute for Polar and Marine

Research, Am Handelshafen 12, 27570

Bremerhaven, Germany

This error was Nature's, not the author's. The caption supplied by the photo library was incorrect - Correspondence Editor, Nature. 